\title{
Risk Factors for COVID-19 Mortality Among People Living with HIV: A Scoping Review
}

\author{
Karan Varshney ${ }^{1,2}$ (D) Prerana Ghosh ${ }^{2} \cdot$ Helena Stiles $^{2} \cdot$ Rosemary Iriowen $^{1}$
}

Accepted: 31 December 2021 / Published online: 13 January 2022

(c) The Author(s) 2022

\begin{abstract}
People living with HIV (PLWH) are particularly vulnerable to worsened outcomes of COVID-19. Therefore, the purpose of this work was to provide a scoping review of the literature to assess the risk factors for COVID-19 mortality among PLWH. Following the Preferred Reporting Items for Systematic Reviews and Meta-Analyses Extension for Scoping Reviews (PRISMA-ScR), searches were conducted in PubMed, Scopus, Global Health, and WHO Coronavirus Database. Articles were eligible for inclusion if they were in English, included PLWH who died after COVID-19 infection, and described risk factors for mortality. Results were descriptively synthesized and pooled thereafter. Study quality was assessed using the Joanna Brigg Institute's critical appraisal tools. 20 studies were eligible for inclusion, with the pooled death rate being $11.7 \%$. Age was a major risk factor, especially after $50(23.2 \%)$ and after $70(41.8 \%)$, and males had a death rate nearly double that of females. As total comorbidities increased, the death rate also greatly increased; among those with comorbidities, the highest fatality rates were those with cardiovascular disease (30.2\%), chronic kidney disease (23.5\%), obesity (22.4\%), and diabetes $(18.4 \%)$. Other risk factors for mortality among PLWH included having a Black racial background, being an injection drug user, being a smoker, and having a CD4 cell count below 200. There is a need to better study confounding factors, and to understand how vaccination influences mortality risk. Overall, the findings highlight a need to ensure that focus is placed on the varying demographics of PLWH amidst COVID-19 control efforts.
\end{abstract}

Keywords COVID-19 $\cdot$ SARS-COV-2 $\cdot$ HIV $\cdot$ Mortality $\cdot$ Adherence $\cdot$ Risk factors

\section{Introduction}

The COVID-19 pandemic has immensely impacted the health status of diverse populations. As of December 23rd, 2021, there have been $276,436,619$ confirmed cases of COVID-19 worldwide, and 5,374,744 deaths [1]. Though it has no restraint on who it affects, the trajectory of the

Karan Varshney

kvarshney@deakin.edu.au

Prerana Ghosh

ghoshpr@deakin.edu.au

Helena Stiles

hfstiles@gmail.com

Rosemary Iriowen

roseiriowen@gmail.com

1 College of Population Health, Thomas Jefferson University, Philadelphia, PA, USA

2 School of Medicine, Deakin University, 75 Pigdons Rd, Waurn Ponds, VIC 3216, Australia pandemic's effects and outcomes varies among populations. One such population that may be particularly vulnerable, due to their compromised immune statuses, is people living with HIV (PLWH).

As of 2020, there were $37,600,000$ PLWH worldwide and 690,000 people who died due to HIV-related causes [2]. PLWH have a higher prevalence of comorbidities, higher mortality rate, are hospitalized at twice the rate of those without HIV and have a healthcare cost approximately four times those without HIV [3]. 73\% of people living with HIV received antiretroviral therapies (ARTs) in 2020 [2]. As PLWH on ARTs live longer, many of them will have pre-existing chronic disease conditions which have been associated with severe COVID-19 co-infection [4]. Despite being on treatment, PLWH on ARTs consistently have a high rate of comorbidities including cardiovascular disease (CVD), sexually transmitted diseases, mental health conditions, neoplasms, diabetes, obesity, and chronic respiratory disease $[4,5]$. 
The presence of comorbidities has consistently shown to be a risk factor for worsened outcomes among COVID-19 patients. Such comorbidities include hypertension, diabetes, CVD, and cerebrovascular disease [6]. However, prior systematic reviews focusing on whether HIV also increases likelihood of death by COVID-19 have provided conflicting findings [7-11]. Furthermore, these reviews have also offered limited insights regarding the risk factors for mortality [7-11].

In consideration of the uncertainty of previous findings, there is a need to better understand the relationship between COVID-19 among PLWH, and the overall risks for poor outcomes. While Mirzaei et al. (2021) [12] have completed a review on the clinical characteristics of patients coinfected with HIV and COVID-19, this was considerably earlier on in the pandemic and was limited to studies conducted before July 2020. Furthermore, that review was largely restricted to case reports and case series, and therefore had a limited total number of pooled patients [12]. This indicates that there is an urgent need to provide updated information in this area of research. The purpose of this study was hence to conduct a scoping review of the literature to provide an updated assessment of the risk factors for COVID-19 mortality among PLWH.

\section{Methods}

This scoping review followed the Preferred Reporting Items for Systematic Review and Meta-Analyses Extension for Scoping Reviews (PRISMA-ScR) [13]. The steps involved for this project involved (1) developing the research question, (2) creating search terms in databases, (3) conducting searches, (4) selecting eligible studies, (5) charting of data and conducting quality assessments, (6) and describing and reporting of the findings. There was no registered study protocol for this review.

On July 20, 2021, searches were conducted in four different databases: PubMed, Scopus, WHO Coronavirus Database, and Global Health. As our population of interest was PLWH who died of COVID-19, searches included relevant terms on HIV, COVID-19, and mortality. No restrictions were placed based on date or language in these searches. Full search terms, with the respective database, are listed in Supplementary Table 1.

Original research studies eligible for inclusion were required to have a minimum of five PLWH who died while infected with COVID-19 and provided stratified data with characteristics of the patients who died. Studies were also required to be in English. To keep the inclusion criteria as broad as possible, peer-reviewed articles and pre-print papers were eligible, and there were no restrictions placed on study type, or date of publication.
After completion of the initial searches, two researchers (KV and PG) independently screened articles. Duplicates were first removed, and articles were thereafter screened by title and abstract. The remaining articles underwent full-text analysis and were excluded if they did not meet the criteria for inclusion. Discrepancies of selected articles among the two researchers were evaluated until consensus was reached about the final articles for inclusion.

Study characteristics, as well as patient data, were next extracted from the final articles. The characteristics of the studies considered were city and country of the study, source of data, study design, and proportion of deaths among PLWH infected with COVID-19. Patient data that was extracted included patient total, sex, age, race, comorbidities, HIV viral load, CD4 cell count (per $\mathrm{mm}^{3}$ ), as well as additional features relevant to patient outcomes that were discussed in the study. The additional features included (but were not limited to) the following: a history of an AIDS diagnosis, men who have sex with men (MSM), injection drug use (IDU), smoking status, and having had the influenza vaccination. Thereafter, a pooled analysis was conducted to determine the overall and stratified case-fatality rate. Data was synthesized and analysed descriptively, with the use of MS excel sheets.

All included studies were assessed for methodological quality using the Joanna Briggs Institute's (JBI) critical appraisal tools [14]. As has been conducted in other reviews $[15,16]$, the tools were altered to provide a numeric score, with cohort studies on an eleven-item scale, case reports on an eight-item scale, case series on a ten-item scale, and cross-sectional studies on an eight-item scale. These numeric scores were used to compare differences in methodological quality across studies.

\section{Results}

Searches from all databases produced a total of 1192 articles. 938 articles remained after removal of duplicates, and after screening by title and abstract, 63 articles remained. A total of 20 articles [17-36] met the inclusion criteria and hence were included in our analysis; 43 articles were removed, with reason. Figure 1 shows the entire screening process for this review.

Characteristics of the included studies are listed in Table 1. Studies were conducted in seven different countries: United States of America (USA) $(\mathrm{n}=10)[19,22,25$, 27-29, 32-35], South Africa (SA) $(n=4)[18,26,30,36]$, United Kingdom (UK) $(n=2)[17,24]$, Brazil $(n=1)$ [31], Chile $(n=1)$ [20], Zambia $(n=1)$ [21], and Spain $(n=1)$ [23]. 18 of the studies had a cohort design [17-29, 31-33, $35,36]$, whereas there was one case series [34], and one cross-sectional analysis [30]. 
Fig. 1 Process of searching and selecting articles included in the scoping review based on the PRISMA 2020 flow diagram [13]

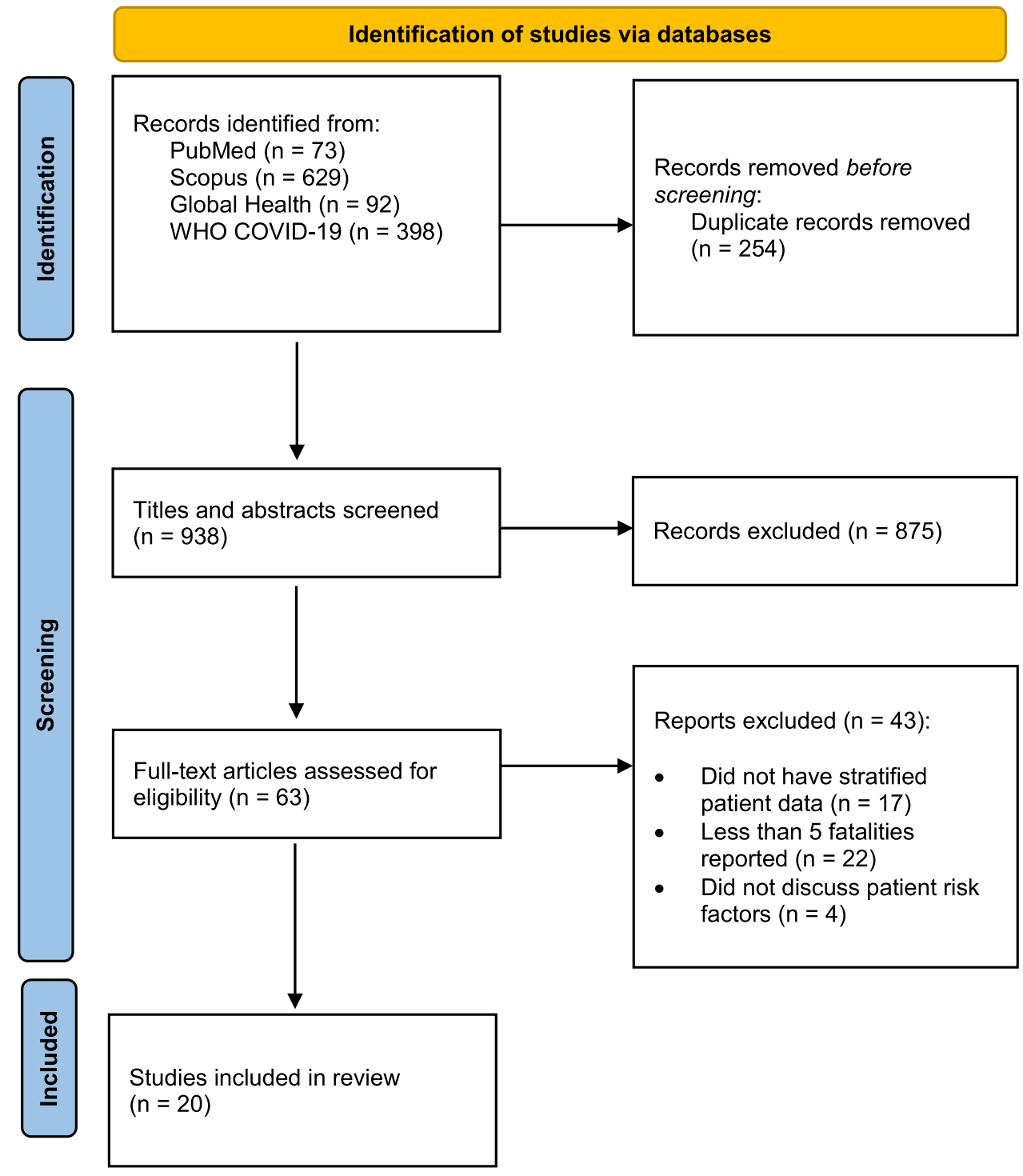

Quality assessment scores for the cohort studies ranged from $6 / 11$ to $10 / 11$ (mean $=8.1$ ), $5 / 8$ for the cross-sectional study, and $6 / 10$ for the case series. Figure 2 depicts the scores (\% yes/no) for the quality assessments. The most frequent study design limitations involved issues with describing factors contributing to loss to follow-up, a lack of utilization of strategies to address incomplete follow-up, limited identification of confounding factors, and a lack of strategies to address confounding factors if they had been identified. Full quality assessment checklists are listed in Supplementary Tables 2-4.

Case-fatality rates among studies ranged from 2.9 [18] to $32.5 \%$ [31]. A single study did not include total cases of COVID-19 among PLWH [17]. The findings of the pooled analysis are listed in Table 2 . The pooled case-fatality rate for cases of COVID-19 among PLWH was 11.7\% (1919 deaths among 16,450 cases). Patient characteristics for all of those who died in each study are listed in Supplementary Table 5.

Amongst racial groups, it was found that Black individuals had the highest fatality rate (12.9\%), followed by Hispanic/Latino individuals (10.3\%), then White individuals $(10.0 \%)$, with people of other races having the lowest rate $(8.3 \%)$. Total COVID-19 case rates were also highest amongst Blacks, followed by Hispanics/Latinos.

Males were found to have a mortality rate nearly double that of females ( $10.1 \%$ and $5.4 \%$ respectively). In terms of age, there was a consistent trend showing that an increase in age corresponds to a markedly higher risk of mortality. These differences were largest amongst those 70 years and above, who had a case-fatality rate of $41.8 \%$, compared to those under 40 years of age, who had a fatality rate of $1.2 \%$. There was also found to be a near five times increase in death rates for those above the age of 50, with those of age 


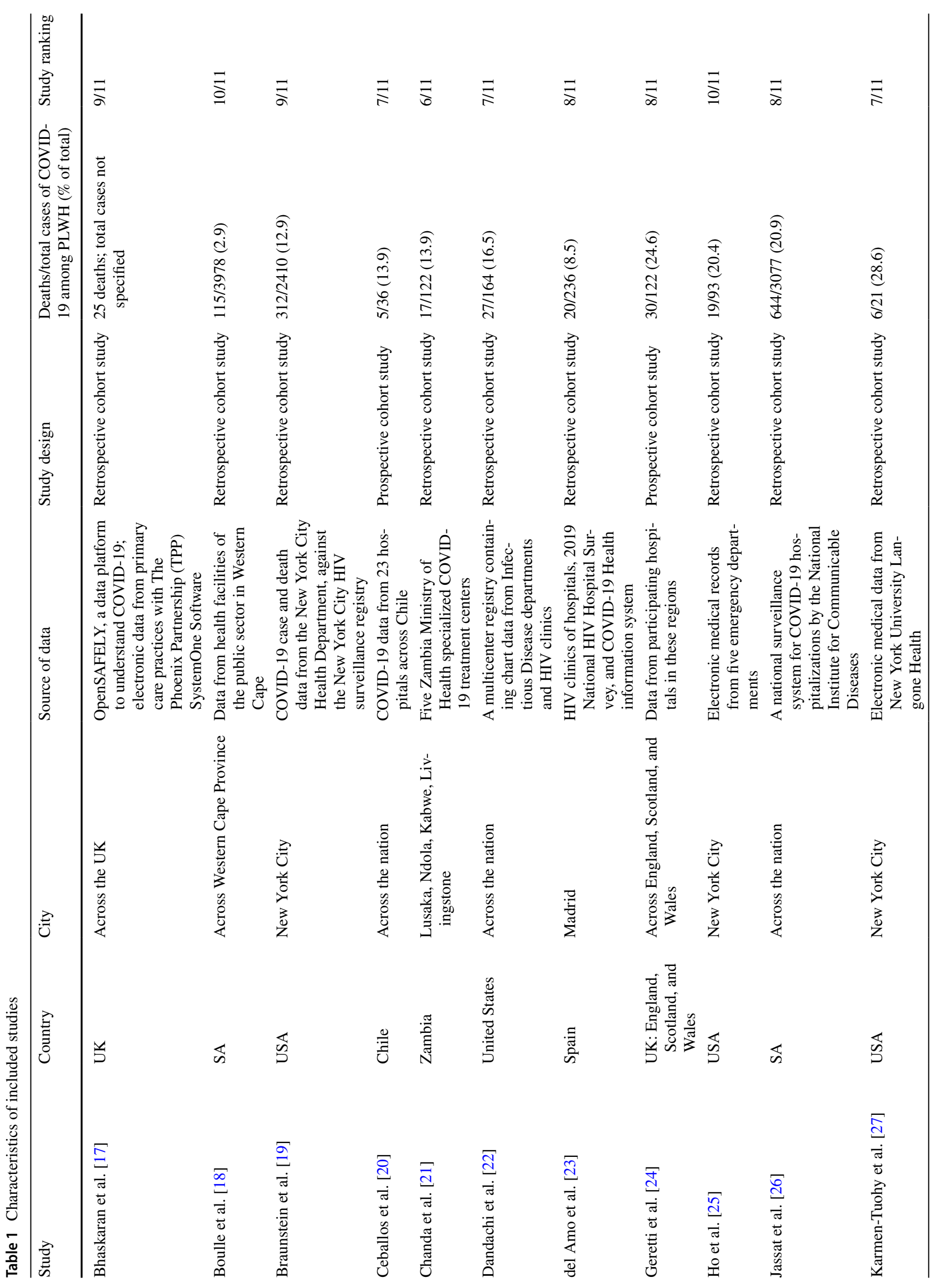




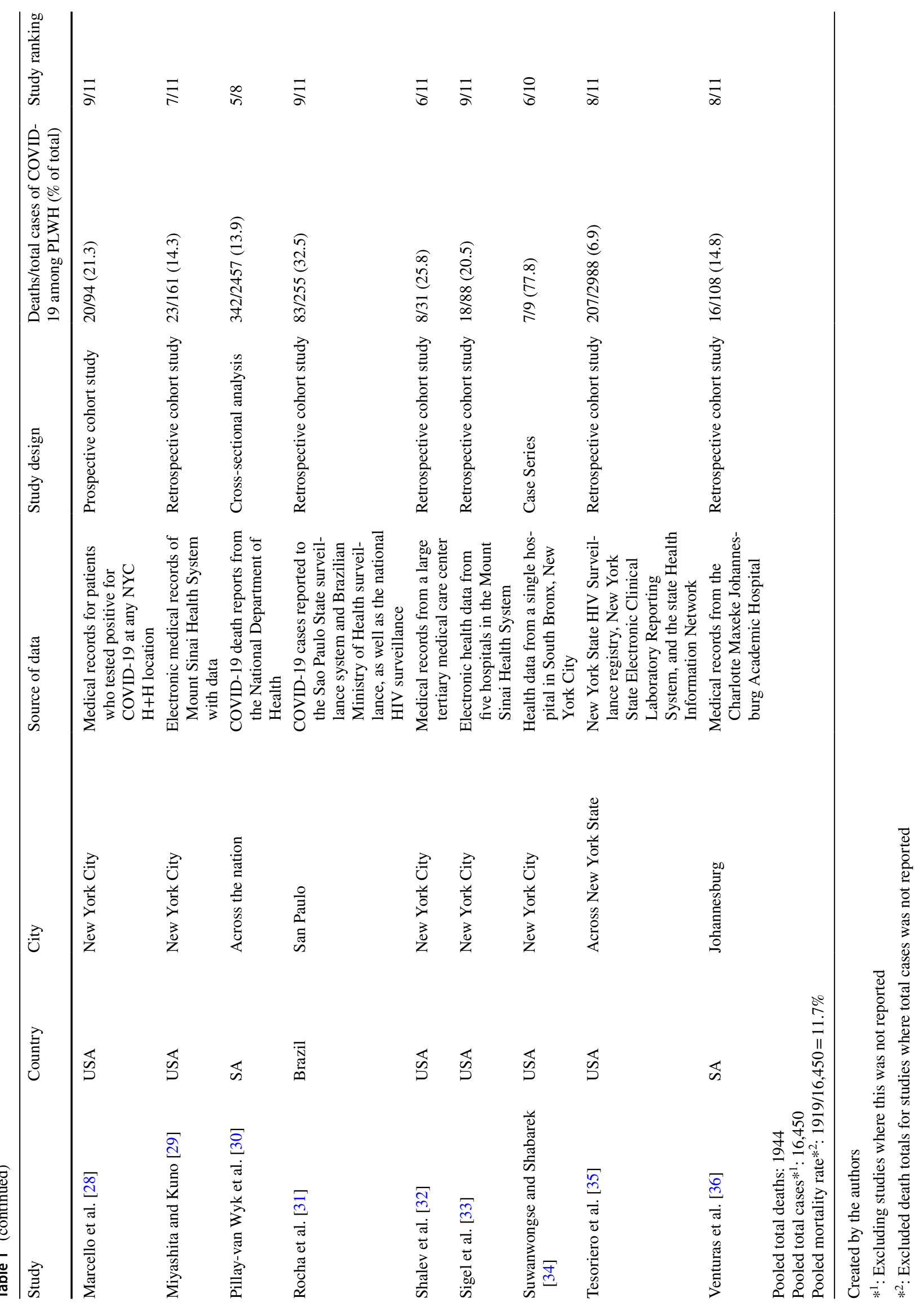




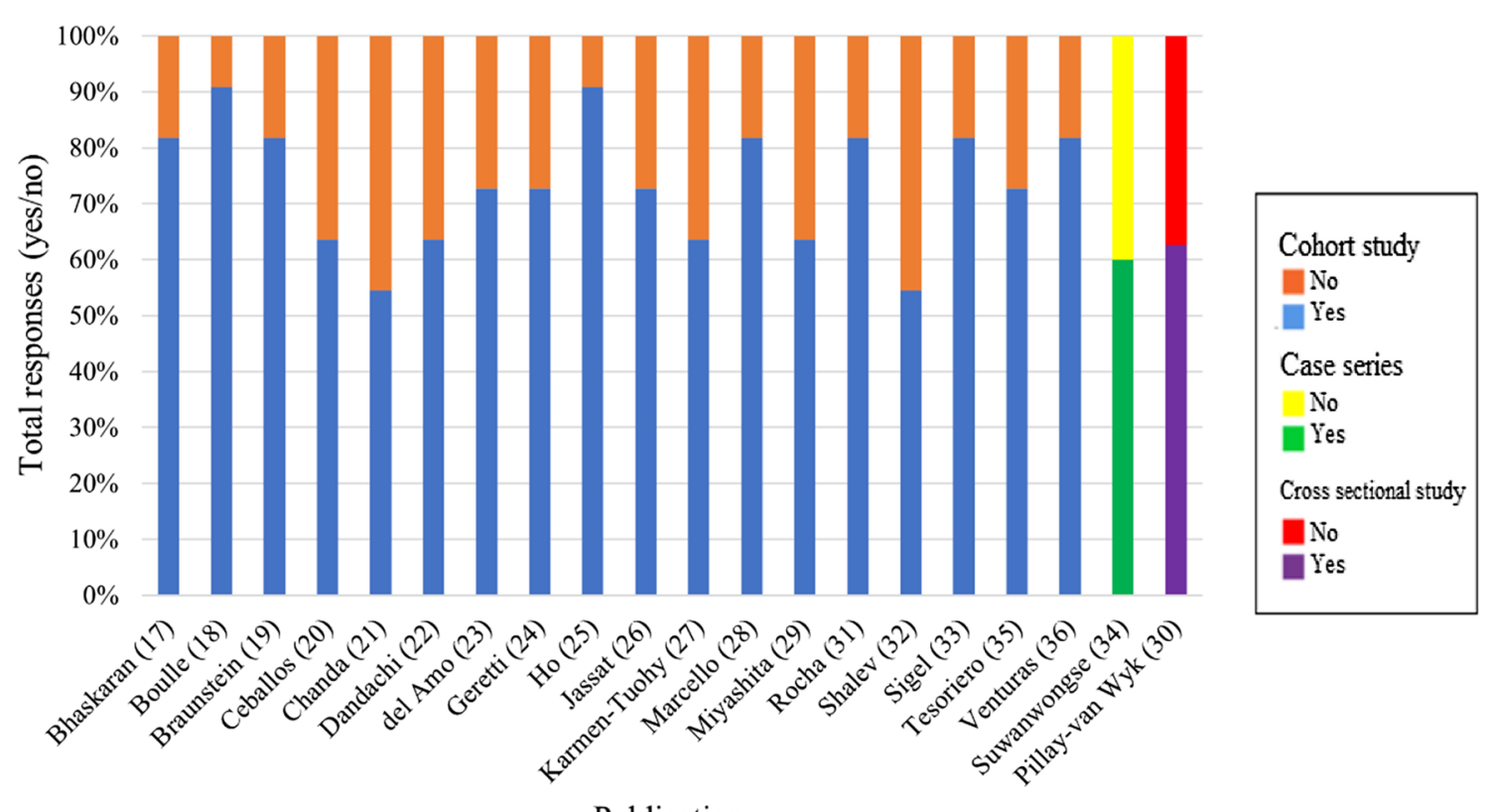

Fig. 2 Quality assessment scores for included publications reported as "yes" or "no" for achieving quality metrics per the Joanna Briggs Institute's critical appraisal tools. Created by the authors

$40-49$ having a rate of $2.7 \%$, and those $50-59$ having a rate of $10.1 \%$.

In the pooled analysis, death rates among those with and without viral suppression were relatively similar, at $14.2 \%$ amongst those virally suppressed, and $14.7 \%$ for those who were virally unsuppressed. A lower CD4 cell count did have an impact on fatality rates; those with a CD4 count under 200 had a death rate of $34.2 \%$, compared to $22.9 \%$ for those with a CD4 count above 200. A single study, which compared fatality rates amongst patients, showed that those with a viral load above 1000 copies/mL or a CD4 count below 200 had an adjusted hazards ratio of 3.80 (95\% CI: 2.07, 6.95) [18].

The presence of comorbidities also led to a higher death rate among patients. Those with one or more comorbidities had a fatality rate of $22.3 \%$, and this increased to $47.8 \%$ for patients with two or more, and $61.3 \%$ for those with three or more. CVD (other than hypertension) patients had an elevated case-fatality rate of $30.2 \%$, as well as diabetes patients $(18.4 \%)$, obese patients $(22.4 \%)$, and CKD patients (23.5\%). Patients with hypertension had lower death rates (7.9\%), along with patients with chronic obstructive pulmonary disease (COPD) (6.7\%) and current or past tuberculosis $(5.4 \%)$.

There were varying trends for the additional factors. Patients with a history of an AIDS diagnosis had a fatality rate of $33.6 \%$, though this factor was only evaluated in a single study [19]; in that study, patients without an AIDS diagnosis also had a death rate above the pooled fatality rate $(23.4 \%)$. Patients with the following factors also had elevated death rates: current/past smoker (27.8\%), being vaccinated for influenza $(27.3 \%)$, bacterial superinfection (100.0\%), IDU (15.7\%), IDU amongst MSM (70.0\%). MSM, as a whole, had lower death rates $(7.1 \%)$.

\section{Discussion}

The findings of this scoping review provide further evidence indicating that PLWH are at a high risk of COVID-19 mortality, with the case-fatality rate among PLWH patients included in this review being $11.7 \%$. Based on these high mortality rates, it is evident that extra support and services are needed during the pandemic in order improve outcomes for this population. One way this can happen is with the expansion of telemedicine services for this demographic. Considering that telemedicine services have been shown in previous studies to be effective in supporting PLWH both prior to [37, 38], and during [39, 40], the COVID-19 pandemic, expansion of these services may be capable of improving patient outcomes. Additionally, increasing access to counselling services, pharmacy services, and social services have been shown to be beneficial to PLWH during the COVID-19 pandemic [41]. Scaling up of these services is hence recommended, alongside studies to determine their overall effectiveness in lowering mortality rates.

Our review has shown that a substantial proportion of PLWH were either virally unsuppressed or had a low CD4 
Table 2 Pooled analysis of case-fatality rate by risk factor

\begin{tabular}{|c|c|}
\hline Risk factor & Deaths/cases $(\%)$ \\
\hline Total & $1919 / 16,450(11.7)$ \\
\hline \multicolumn{2}{|l|}{ Race } \\
\hline Black & $337 / 2604(12.9)$ \\
\hline Hispanic/Latino & $239 / 2321(10.3)$ \\
\hline White & $74 / 738(10.0)$ \\
\hline Other & $29 / 348(8.3)$ \\
\hline \multicolumn{2}{|l|}{ Sex } \\
\hline Male & $537 / 5300(10.1)$ \\
\hline Female & $265 / 4878(5.4)$ \\
\hline \multicolumn{2}{|l|}{ Age } \\
\hline $70+$ & $82 / 196(41.8)$ \\
\hline $60+$ & $398 / 2015(19.5)$ \\
\hline $50+$ & $467 / 2015(23.2)$ \\
\hline $40+$ & $614 / 5540(11.1)$ \\
\hline$<40$ & $34 / 2830(1.2)$ \\
\hline $50-59$ & $60 / 594(10.1)$ \\
\hline $40-49$ & $34 / 1244(2.7)$ \\
\hline \multicolumn{2}{|l|}{ Viral load } \\
\hline Virally suppressed & $544 / 3844(14.2)$ \\
\hline Virally unsuppressed & $97 / 659(14.7)$ \\
\hline \multicolumn{2}{|l|}{ CD4 count (per mm $\left.\mathrm{m}^{3}\right)$} \\
\hline $200+$ & 453/1974 (22.9) \\
\hline$<200$ & $251 / 733(34.2)$ \\
\hline \multicolumn{2}{|l|}{ Comorbidities } \\
\hline $1+$ comorbidities & $424 / 1877(22.3)$ \\
\hline $2+$ comorbidities & $43 / 90(47.8)$ \\
\hline $3+$ comorbidities & $19 / 31(61.3)$ \\
\hline Hypertension & $62 / 784(7.9)$ \\
\hline Diabetes & $79 / 430(18.4)$ \\
\hline $\begin{array}{l}\text { Cardiovascular disease (other than hyperten- } \\
\text { sion) }\end{array}$ & $13 / 43(30.2)$ \\
\hline Obesity & $13 / 58(22.4)$ \\
\hline Chronic kidney disease (CKD) & $32 / 136(23.5)$ \\
\hline $\begin{array}{l}\text { Chronic obstructive pulmonary disease } \\
\text { (COPD) }\end{array}$ & $17 / 254(6.7)$ \\
\hline Cancer & $3 / 23(13.0)$ \\
\hline Neuropsychiatric disease & $3 / 12(25.0)$ \\
\hline Previous organ transplant & $3 / 4(75.0)$ \\
\hline Hyperlipidemia & $3 / 4(75.0)$ \\
\hline Chronic liver disease & $1 / 3(33.3)$ \\
\hline Past/current tuberculosis & $59 / 1102(5.4)$ \\
\hline Hepatitis C & $2 / 3(66.6)$ \\
\hline Syphilis & $0 / 1(0.0)$ \\
\hline Bacterial superinfection & $3 / 3(100.0)$ \\
\hline Influenza vaccination received & $12 / 44(27.3)$ \\
\hline \multicolumn{2}{|l|}{ History of AIDS diagnosis } \\
\hline Yes & $249 / 742(33.6)$ \\
\hline No & $63 / 269(23.4)$ \\
\hline Current/past smoker & $15 / 54(27.8)$ \\
\hline Men who have sex with men (MSM) & $133 / 1875(7.1)$ \\
\hline
\end{tabular}

Table 2 (continued)

\begin{tabular}{ll}
\hline Risk factor & Deaths/cases (\%) \\
\hline Injection drug user (IDU) & $126 / 803(15.7)$ \\
MSM \& IDU & $14 / 20(70.0)$ \\
\hline
\end{tabular}

Created by the authors

cell count; those with a lower CD4 count had a particularly high risk of death. A possible explanation for this is an interruption of adherence to ARTs due to social distancing measures during the COVID-19 pandemic, as this is a problem that has been described in numerous different contexts [6, 42]. Alongside a need for more research on this issue, this indicates that considerations should be made for scaling up of HIV treatment adherence programs alongside increased pandemic control efforts. One such program, which has previously been shown to be effective in meeting emergency needs for PLWH in a variety of contexts during the COVID-19 pandemic, involves the provision of ARTs via home delivery [43]. Programs such as this could possibly be expanded to help to ensure that PLWH also receive other services and resources, such as food, masks, and other essential items.

When considering race, it is evident that PLWH who are Black are at a particularly elevated risk of contracting, and dying from, COVID-19 compared to those of other racial groups. These findings have important implications, and further highlight the consequences of racial inequities during the COVID-19 pandemic. Our work hence shows that there is a need to create more programs that are specifically directed towards helping Black individuals amidst the pandemic, particularly across the United States. Therefore, targeted vaccination campaigns, along with resource allocation programs, have the potential to have a sizeable impact. Furthermore, prior research has indicated that medical mistrust regarding COVID-19 among HIV-positive Black individuals may be a contributor to health inequities [44]. Addressing this mistrust with community engagement may also be pivotal in improving COVID-19 outcomes among HIV-positive Black individuals [44].

There is a striking difference in death rates among people of different sexes, and for people of different age groups. Males were nearly twice as likely to die from COVID-19 than females, and PLWH above the age of 70 had a death rate nearly 35 times higher than those under 40 . It is worthwhile denoting that comparable trends have also been seen among COVID-19 patients not living with HIV [45]. Studying how gender may influence mortality rates and ensuring that older PLWH with COVID-19 have increased access to care will therefore be important.

Based on the findings, it is unclear if MSM are at a higher risk of death. The findings do however show that IDU are at 
a higher risk of death, and risk of fatality is especially high amongst IDU who are also MSM. Previous research has provided an indication that, during the COVID-19 pandemic, IDU have had lower ART adherence rates and increased rates of illicit substance use overall, and this may be attributed to increased social-distancing measures [46]. There is hence a clear need to support IDU during the pandemic by creating and scaling-up programs that can offer harm-reduction, syringe exchange, and easier access to ARTs [46-50]. It has also been proposed that mobile-health interventions may serve as an effective way to support IDU during pandemics [46], but the evidence for this is limited. Based on this, it is also recommended that future research assess and evaluate the type of interventions that can most optimally lower mortality rates of IDU living with HIV and COVID- 19.

The presence of comorbidities was shown to correspond to high death rates, with those living with multiple comorbidities having especially high rates of death. CVD, obesity, $\mathrm{CKD}$, and diabetes are all conditions which appear to elevate death rates, along with smoking. However, an opposite pattern was observed for those with hypertension, COPD, and tuberculosis. Furthermore, there was limited patient data for those with cancer, neuropsychiatric disease, organ transplants, hyperlipidemia, and bacterial superinfection. This emphasizes a need to better understand the risk due to specific comorbidities for this demographic. Similarly, it would be beneficial to better understand the effects of influenza vaccinations, and whether they may be beneficial, or even detrimental for this group.

Notably, of the studies included in this review, there were no case-control studies included. This hence restricted the capability to compare outcomes for COVID-19 patients who did, and did not, have HIV. Additionally, while there were a small number of high-quality studies, many of the included studies were either of moderate or low quality and did not appropriately account for confounding factors. It is hence recommended that more high-quality studies, with controls, be conducted to better understand the factors that place PLWH at risk of COVID-19 mortality.

There are several important limitations to consider. First, none of the studies provided data on the effects of COVID19 vaccination, and the extent to which this impacts risk. Secondly, as half of the studies are from USA, it is not entirely clear how much findings from these settings can be generalized to other nations. Furthermore, the findings do not provide a clear indication as to whether having an elevated viral load influences overall fatality rates; considering that many of the social distancing measures during the COVID-19 pandemic have previously shown to impact medication adherence $[6,42]$, there is a clear need to better understand the implications of this on COVID-19 outcomes. It is hence recommended that future studies be conducted to determine if ART adherence rates have decreased, and the reasons for this. This will be crucial, as emphasized by the fact that those with a lower CD4 cell count had a particularly high risk of death.

\section{Conclusions}

PLWH are at a high risk for death by COVID-19. Risk factors for death were found to be having a Black racial background, living with comorbidities, being an IDU, being older, having a low CD4 cell count, and being male. Targeted interventions and pandemic control efforts towards individuals with these risk factors will be imperative to effectively save lives of PLWH during the COVID-19 pandemic.

Supplementary Information The online version contains supplementary material available at https://doi.org/10.1007/s10461-022-03578-9.

Acknowledgements No funding was received for this research.

Author Contributions KV proposed the research question, developed the research project design, served as a first reviewer for the PRISMA workflow, synthesised the data, wrote major portions of the manuscript and edited the manuscript. PG served as a second reviewer for the PRISMA workflow, made written contributions to the manuscript and edits. HS made contributions to the writing of the manuscript and edits. RI made edits, minor contributions to the writing, and provided insights during the project design.

Funding Open Access funding enabled and organized by CAUL and its Member Institutions. This research received no specific grant from any funding agency in the public, commercial or not-for-profit sectors.

\section{Declarations}

Conflict of interest The authors have no conflicts of interests to disclose.

Open Access This article is licensed under a Creative Commons Attribution 4.0 International License, which permits use, sharing, adaptation, distribution and reproduction in any medium or format, as long as you give appropriate credit to the original author(s) and the source, provide a link to the Creative Commons licence, and indicate if changes were made. The images or other third party material in this article are included in the article's Creative Commons licence, unless indicated otherwise in a credit line to the material. If material is not included in the article's Creative Commons licence and your intended use is not permitted by statutory regulation or exceeds the permitted use, you will need to obtain permission directly from the copyright holder. To view a copy of this licence, visit http://creativecommons.org/licenses/by/4.0/.

\section{References}

1. World Health Organization (WHO). WHO Coronavirus (COVID19) dashboard. (2021). https://covid19.who.int/. Accessed 11 Aug 2021. 
2. World Health Organization (WHO). HIV data and statistics. (2021). https://www.who.int/teams/global-hiv-hepatitis-and-stisprogrammes/hiv/strategic-information/hiv-data-and-statistics. Accessed 22 June 2021.

3. Pourcher V, Gourmelen J, Bureau I, Bouee S. Comorbidities in people living with HIV: an epidemiologic and economic analysis using a claims database in France. PLoS ONE. 2020;15(12):e0243529.

4. Garrido-Hernansaiz H, Heylen E, Bharat S, Ramakrishna J, Ekstrand ML. Stigmas, symptom severity and perceived social support predict quality of life for PLHIV in urban Indian context. Health Qual Life Outcomes. 2016;14(1):152.

5. De Francesco D, Underwood J, Bagkeris E, Anderson J, Williams I, Vera J, Post F, Boffito M, Johnson M, Mallon P, Winston A, Sabin C. Risk factors and impact of patterns of cooccurring comorbidities in people living with HIV. AIDS. 2019;33(12):1871-80.

6. Waterfield KC, Shah GH, Etheredge GD, Ikhile O. Consequences of COVID-19 crisis for persons with HIV: the impact of social determinants of health. BMC Public Health. 2021;21(1):1-7.

7. Cooper TJ, Woodward BL, Alom S, Harky A. Coronavirus disease 2019 (COVID-19) outcomes in HIV/AIDS patients: a systematic review. HIV Med. 2020;21(9):567-77.

8. Liang M, Luo N, Chen M, Chen C, Singh S, Singh S, Tan S. Prevalence and mortality due to COVID-19 in HIV co-infected population: a systematic review and meta-analysis. Infect Dis Ther. 2021. https://doi.org/10.1007/s40121-021-00447-1.

9. Dong Y, Li Z, Ding S, Liu S, Tang Z, Jia L, Liu Y. HIV infection and risk of COVID-19 mortality: a meta-analysis. Medicine. 2021;100(26):e26573.

10. Ssentongo P, Heilbrunn ES, Ssentongo AE, Advani S, Chinchilli VM, Nunez JJ, Du P. Epidemiology and outcomes of COVID19 in HIV-infected individuals: a systematic review and metaanalysis. Sci Rep. 2021;11(1):1-12.

11. Mellor MM, Bast AC, Jones NR, Roberts NW, Ordóñez-Mena JM, Reith AJ, Dorward J. Risk of adverse coronavirus disease 2019 outcomes for people living with HIV. AIDS (London, England). 2021;35(4):F1.

12. Mirzaei H, McFarland W, Karamouzian M, Sharifi H. COVID19 among people living with HIV: a systematic review. AIDS Behav. 2021;25(85-92):2021. https://doi.org/10.1007/ s10461-020-02983-2.

13. Tricco AC, Lillie E, Zarin W, O'Brien KK, Colquhoun H, Levac D, Moher D, Peters MD, Horsley T, Weeks L, Hempel S, et al. PRISMA extension for scoping reviews (PRISMA-ScR): checklist and explanation. Ann Intern Med. 2018;169(7):467-73. https:// doi.org/10.7326/M18-0850.

14. Joanna Briggs Institute. Critical appraisal tools. 2020. https://jbi. global/critical-appraisal-tools. Accessed 14 Apr 2021.

15. Bowring AL, Veronese V, Doyle JS, Stoove M, Hellard M. HIV and sexual risk among men who have sex with men and women in Asia: a systematic review and meta-analysis. AIDS Behav. 2016;20(10):2243-65. https://doi.org/10.1007/ s10461-015-1281-x.

16. Xu Y, Chen X, Wang K. Global prevalence of hypertension among people living with HIV: a systematic review and meta-analysis. J Am Soc Hypertens. 2017;11(8):530-40. https://doi.org/10.1016/j. jash.2017.06.004

17. Bhaskaran K, Rentsch CT, MacKenna B, Schultze A, Mehrkar A, Bates CJ, et al. HIV infection and COVID-19 death: a population-based cohort analysis of UK primary care data and linked national death registrations within the OpenSAFELY platform. Lancet HIV. 2021;8(1):e24-32

18. Boulle A, Davies M, Hussey H, Ismail M, Morden E, Vundle Z, et al. Risk factors for COVID-19 death in a population cohort study from the Western Cape Province, South Africa. Clin Infect Dis. 2020. https://doi.org/10.1093/cid/ciaa1198.

19. Braunstein SL, Lazar R, Wahnich A, Daskalakis DC, Blackstock OJ. COVID-19 infection among people with HIV in New York City: a population-level analysis of linked surveillance data. Clin Infect Dis. 2020. https://doi.org/10.1093/cid/ciaa1793.

20. Ceballos ME, Ross P, Lasso M, Dominguez I, Puente M, Valenzuela $\mathrm{P}$, et al. Clinical characteristics and outcomes of people living with HIV hospitalized with COVID-19: a nationwide experience. Int J STD AIDS. 2021;32(5):435-43.

21. Chanda D, Minchella PA, Kampamba D, Itoh M, Hines JZ, Fwoloshi S, et al. COVID-19 severity and COVID-19-associated deaths among hospitalized patients with HIV infectionZambia, March-December 2020. Morb Mortal Wkly Rep. 2021;70(22):807-10.

22. Dandachi D, Geiger G, Montgomery MW, Karmen-Tuohy S, Golzy M, Antar AAR, et al. Characteristics, comorbidities, and outcomes in a multicenter registry of patients with HIV and coronavirus disease-19. Clin Infect Dis. 2020. https://doi.org/10.1093/ cid/ciaa1339.

23. del Amo J, Polo R, Moreno S, Díaz A, Martínez E, Arribas JR, et al. Incidence and severity of COVID-19 in HIV-positive persons receiving antiretroviral therapy: a cohort study. Ann Intern Med. 2020;173(7):536-41.

24. Geretti AM, Stockdale AJ, Kelly SH, Cevik M, Collins S, Waters $\mathrm{L}$, et al. Outcomes of COVID-19 related hospitalization among people with HIV in the ISARIC WHO Clinical Characterization Protocol (UK): a prospective observational study. Clin Infect Dis. 2020. https://doi.org/10.1093/cid/ciaa1605.

25. Ho HE, Peluso MJ, Margus C, Matias Lopes JP, He C, Gaisa $\mathrm{MM}$, et al. Clinical outcomes and immunologic characteristics of Covid-19 in people with HIV. J Infect Dis. 2020. https://doi.org/ 10.1093/infdis/jiaa380.

26. Jassat W, Cohen C, Tempia S, Masha M, Goldstein S, KufaChakezha T, et al. A National cohort study of COVID-19 in-hospital mortality in South Africa: the intersection of communicable and non-communicable chronic diseases in a high HIV prevalence setting. MedRxiv. 2020. https://doi.org/10.1101/2020.12.21.20248 $409 \mathrm{v} 1$.

27. Karmen-Tuohy S, Carlucci PM, Zervou FN, Zacharioudakis IM, Rebick G, Klein E, et al. Outcomes among HIV-positive patients hospitalized with COVID-19. J Acquir Immune Defic Syndr. 2020;85(1):6-10.

28. Marcello RK, Dolle J, Grami S, Adule R, Li Z, Tatem K, New York City Health+ Hospitals COVID-19 Population Health Data Team. Characteristics and outcomes of COVID-19 patients in New York City's public hospital system. PLoS ONE. 2020;15(12):e0243027.

29. Miyashita H, Kuno T. Prognosis of coronavirus disease 2019 (COVID-19) in patients with HIV infection in New York City. HIV Med. 2021. https://doi.org/10.1111/hiv.12920.

30. Pillay-Van Wyk V, Bradshaw D, Groenewald P, Seocharan I, Manda S, Roomaney RA, et al. COVID-19 deaths in South Africa: 99 days since South Africa's first death. S Afr Med J. 2020;110(11):1093-9.

31. Rocha SQ, Avelino-Silva VI, Tancredi MV, Jamal LF, Ferreira PRA, Tayra A, et al. COVID-19 and HIV/AIDS in a cohort study in Sao Paulo, Brazil: outcomes and disparities by race and schooling. AIDS Care. 2021. https://doi.org/10.1080/09540121.2021. 1936444.

32. Shalev N, Scherer M, Lasota ED, Antoniou P, Yin MT, Zucker J, et al. Clinical characteristics and outcomes in people living with human immunodeficiency virus hospitalized for coronavirus disease 2019. Clin Infect Dis. 2020;71(16):2294-7.

33. Sigel K, Swartz T, Golden E, Paranjpe I, Somani S, Richter F, et al. Coronavirus 2019 and people living with human 
immunodeficiency virus: outcomes for hospitalized patients in New York City. Clin Infect Dis. 2020;71(11):2933-8.

34. Suwanwongse K, Shabarek N. Variation in mortality of HIV/ SARS-CoV-2 coinfected patients in the Bronx, New York City. J Med Virol. 2021;93(2):603-5.

35. Tesoriero JM, Swain CAE, Pierce JL, Zamboni L, Wu M, Holtgrave DR, Rosenberg ES. Elevated COVID-19 outcomes among persons living with diagnosed HIV infection in New York State: results from a population-level match of HIV, COVID-19, and hospitalization databases. medRxiv. 2020. https://doi.org/10.1101/ 2020.11.04.20226118.

36. Venturas J, Zamparini J, Shaddock E, Stacey S, Murray L, Richards GA, et al. Comparison of outcomes in HIV-positive and HIVnegative patients with COVID-19. J Infect. 2021. https://doi.org/ 10.1016/j.jinf.2021.05.020

37. Cho H, Iribarren S, Schnall R. Technology-mediated interventions and quality of life for persons living with HIV/AIDS. Appl Clin Inform. 2017;8(02):348-68.

38. Moeckli J, Stewart KR, Ono S, Alexander B, Goss T, Maier M, Tien PC, Howren MB, Ohl ME. Mixed-methods study of uptake of the extension for community health outcomes (ECHO) telemedicine model for rural veterans with HIV. J Rural Health. 2017;33(3):323-31.

39. Rogers BG, Coats CS, Adams E, et al. Development of telemedicine infrastructure at an LGBTQ+ clinic to support HIV prevention and care in response to COVID-19, Providence, RI. AIDS Behav. 2020;24:2743-7. https://doi.org/10.1007/ s10461-020-02895-1.

40. Ender PT, Markson RH, Suri A, Ruppert K, Padron N, Stoltzfus JC, Berges V, Reed R. Rapid implementation of a telemedicine program in a Ryan White-funded HIV clinic during a global pandemic. JAIDS. 2022;89(1):e2-4. https://doi.org/10.1097/QAI. 0000000000002815.

41. Beima-Sofie K, Ortblad KF, Swanson F, et al. "Keep It Going if You Can": HIV service provision for priority populations during the COVID-19 pandemic in Seattle, WA. AIDS Behav. 2020;24:2760-3. https://doi.org/10.1007/s10461-020-02902-5.

42. Fernandes A, Brito AM, Mendes T, Alcobia A. 4CPS-392 effect of COVID-19 pandemic on antiretroviral therapy adherence. BMJ Eur J Hosp Pharm. 2021. https://doi.org/10.1136/ejhpharm-2021eahpconf.224.

43. Hoke T, Bateganya M, Toyo O, Francis C, Shrestha B, Philakone P, Pandey SR, Persaud N, Cassell MM, Wilcher R, Mahler H. How home delivery of antiretroviral drugs ensured uninterrupted HIV treatment during COVID-19: experiences from Indonesia, Laos, Nepal, and Nigeria. Glob Health Sci Pract. 2021;9(4):978-89.

44. Bogart LM, Ojikutu BO, Tyagi K, Klein DJ, Mutchler MG, Dong L, Lawrence SJ, Thomas DR, Kellman S. COVID-19 related medical mistrust, health impacts, and potential vaccine hesitancy among black Americans living with HIV. J Acquir Immune Defic Syndr. 2021;86(2):200-7. https://doi.org/10.1097/QAI.00000 00000002570.

45. Centers for Disease Control and Prevention (CDC). Risk for COVID-19 infection, hospitalization, and death by age group. 2021. Updated 19 July 2021. https://www.cdc.gov/coronavirus/ 2019-ncov/covid-data/investigations-discovery/hospitalizationdeath-by-age.html.

46. Hochstatter KR, Akhtar WZ, Dietz S, et al. Potential influences of the COVID-19 pandemic on drug use and HIV care among people living with HIV and substance use disorders: experience from a pilot mHealth intervention. AIDS Behav. 2021;25:354-9. https:// doi.org/10.1007/s10461-020-02976-1.

47. Broz D, Carnes N, Chapin-Bardales J, Des Jarlais DC, Handanagic S, Jones CM, McClung RP, Asher AK. Syringe services programs' role in ending the HIV epidemic in the US: why we cannot do it without them. Am J Prev Med. 2021;61(5):S118-29.

48. Vasylyeva TI, Smyrnov P, Strathdee S, Friedman SR. Challenges posed by COVID-19 to people who inject drugs and lessons from other outbreaks. J Int AIDS Soc. 2020;23(7):e25583.

49. Chayama KL, Ng C, McNeil R. Calls for access to safe injecting supplies as a critical public health measure during the COVID-19 pandemic. J Addict Med. 2020;14(5):e142-3. https://doi.org/10. 1097/ADM.0000000000000712.

50. Bartholomew TS, Nakamura N, Metsch LR, Tookes HE. Syringe services program (SSP) operational changes during the COVID19 global outbreak. Int J Drug Policy. 2020;83: 102821. https:// doi.org/10.1016/j.drugpo.2020.102821.

Publisher's Note Springer Nature remains neutral with regard to jurisdictional claims in published maps and institutional affiliations. 